\title{
Performance and Production Requirements for the Optical Components in a High-Average-Power Laser System
}

\author{
J. R. Taylor \\ R. Chow \\ F. W. Doss \\ J. N. Wong
}

This paper was prepared for submittal to the 44th Annual Meeting of the International Symposium on

Optical Science, Engineering, and Instrumentation

Denver, Colorado

July 18-23, 1999

July 2, 1999

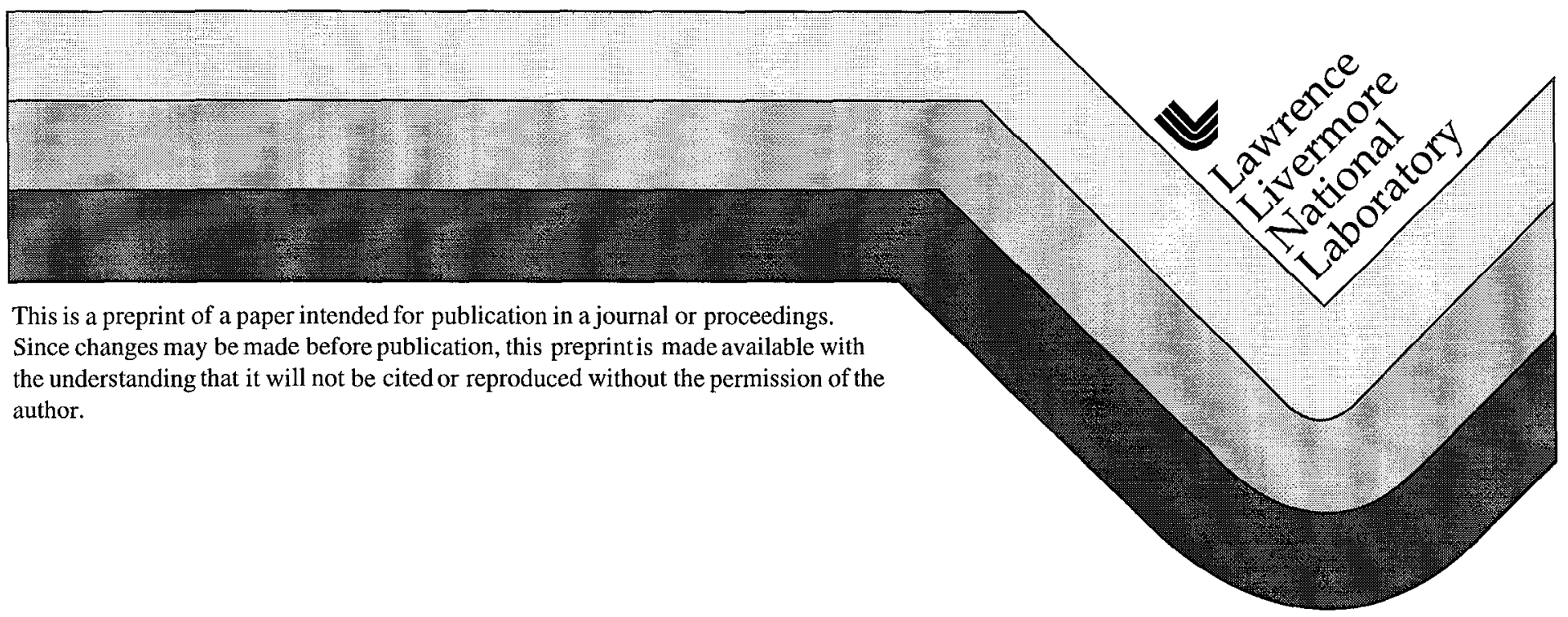




\section{DISCLAIMER}

This document was prepared as an account of work sponsored by an agency of the United States Government. Neither the United States Government nor the University of California nor any of their employees, makes any warranty, express or implied, or assumes any legal liability or responsibility for the accuracy, completeness, or usefulness of any information, apparatus, product, or process disclosed, or represents that its use would not infringe privately owned rights. Reference herein to any specific commercial product, process, or service by trade name, trademark, manufacturer, or otherwise, does not necessarily constitute or imply its endorsement, recommendation, or favoring by the United States Government or the University of California. The views and opinions of authors expressed herein do not necessarily state or reflect those of the United States Government or the University of California, and shall not be used for advertising or product endorsement purposes. 


\title{
Performance and production requirements for the optical components in a high-average-power laser system
}

\author{
by John R. Taylor, Robert Chow, Fred W. Doss, and J. Nan Wong \\ Lawrence Livermore National Laboratory, Livermore, CA 94550
}

Key words: High-average-power laser, coating efficiency, absorption, optical components

\begin{abstract}
Optical components needed for high-average-power lasers, such as those developed for Atomic Vapor Laser Isotope Separation (AVLIS), require high levels of performance and reliability. Over the past two decades, optical component requirements for this purpose have been optimized and performance and reliability have been demonstrated. Many of the optical components that are exposed to the high power laser light affect the quality of the beam as it is transported through the system. The specifications for these optics are described including a few parameters not previously reported and some component manufacturing and testing experience.

\section{Introduction}

Development of Atomic Vapor Laser Isotope Separation (AVLIS) technology was started at the Lawrence Livermore National Laboratory (LLNL) over twenty-five years ago. ${ }^{1}$ The Department of Energy funded this project until the United States Enrichment Corporation (USEC) was created under the Energy Policy Act of 1992 to privatize the U.S. uranium enrichment industry. The USEC was established to assume the responsibility for the enrichment of uranium necessary for the production of nuclear fuel, previously conducted by the Department of Energy. This entails operation of the existing enrichment facilities and development of methods that are more cost effective.

USEC, Inc. was privatized via IPO in July of 1998 . The initial plan was to build a production facility to enrich uranium for use in the generation of electric power utilizing the AVLIS process. ${ }^{2}$ Until June of this year, a series of process demonstrations were underway to demonstrate near plant performance utilizing full scale equipment. Preliminary design was also underway for the production plant that would have employed this technology. In June, USEC announced that it is suspending further development of its AVLIS enrichment technology. The plan to build the AVLIS plant, which would have required over 22,000 optical components, has been suspended. Significant experience in high-average-power, visible lasers and associated optical components has been developed over the years at LLNL. A summary of recent laser progress and a status of optical component manufacturing and testing requirements are provided. ${ }^{3}$
\end{abstract}

\section{AVLIS plant architecture and recent advances}

The $\Lambda$ VLIS laser system consists of dye lasers that are precisely tuned, timed, and formatted to ensure uniform illumination of the uranium vapor. Atoms of selected isotopes in the vapor are excited by the laser energy. This allows separation and collection of the selected isotopes. Pump lasers energize dye molecules in the dye laser oscillator and amplifiers. Although the pump sources have traditionally been copper lasers, advances in solid-state laser technology offer advantages for utilizing that approach. This architecture is illustrated in Figure 1. Diode lasers pump the dye front end while doubled YAG lasers pump the dye amplifiers. The multiple dye chains are then combined along with diagnostic pilot lasers and the red laser system. The combined beams are transported to the separator where the vapor is illuminated. There are approximately 1500 green solid-state pump lasers (130 Watt level), 20 dye front end systems, 36 dye amplifier chains producing over $65 \mathrm{~kW}, 20$ pilot lasers (few watt level), 10 Ti:Sapphire-red lasers (>50 watt level), and 10 low-power, vapor rate monitors. 


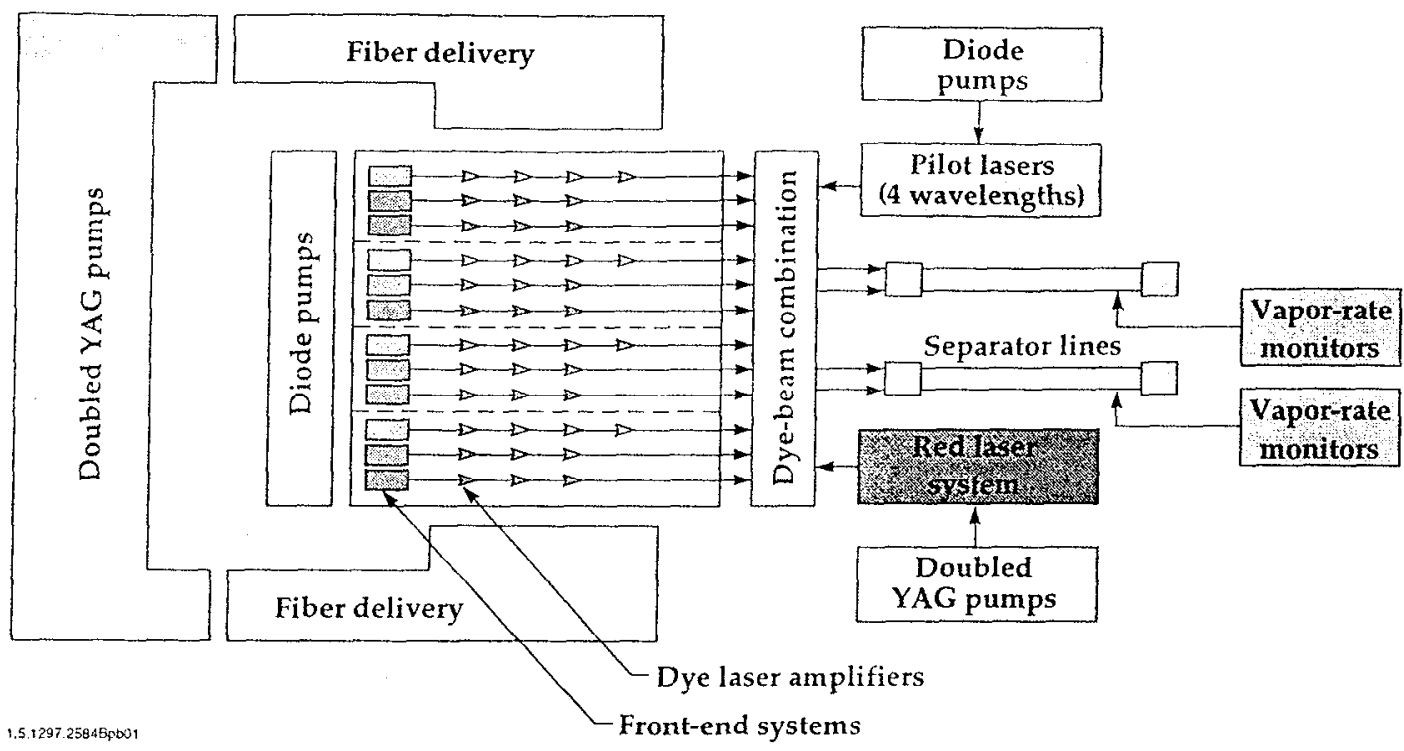

Figure 1. AVLIS plant dye laser system architecture

A concerted effort was made to improve beam quality through control of beam size, wavefront quality, and intensity uniformity. Attention to the interactions between the pump lasers beams, the dye amplifier, and the dye laser beam yielded better understanding and beam quality. Improvements in the diagnostic tools to evaluate beam quality and vapor parameters were implemented to support this work. Improvements were also made in the adaptive optic systems that are used extensively in AVLIS for size and wavefront control. There are 38-actuator mirrors at the end of each chain and simple bendable mirrors placed strategically throughout the transport path. Significant improvements in beam quality were measured over the past year.

A key part of the effort to better understand and improve beam quality was an end-to-end model of the optical system. A complex task due to the sheer size of the system, the model incorporates a wide range of factors that impact beam quality and transport efficiency. This includes optical surface errors that occur from bulk index variations, polishing, coating stress, mounting stress, and vacuum loads. It also includes thermal effects from the heat load of the lasers. Gravity distortion was found to be minimal for these optics and therefore not included in the model. The original model was a Microsoft Excel program using Visual Basic that could project rays through the system.

The latest model was made using CODE $\mathrm{V}^{\text {i }}$ with BEAM PROP, a new diffraction capability developed by Optical Research Associates. The functions of this model are shown schematically in Figure 2. The bulk, surface, and thermal errors are represented by Zernike polynomials. Thermal errors were predicted using the Thermal/Structural/Optical (TSO) Analysis Code developed at LLNL. This code consists of CODE V, mentioned above, along with NIKE3D and TOPAZ3D, also developed at LLNL. ${ }^{+}$This model considers the thermal sensitivity of an optical system including bulk and coating absorption along with the mechanical properties of a given substrate materialand the optical characteristics of the laser beam. ${ }^{5}$

The beam quality measured in the operating laser system can then be compared with the results of the end-to-end model to hetter understand the causes of focusing and beam quality degradation. This comparison can be used to retine the predictive model, propose alternate optical system designs and diagnostics, and predict plant performance.

A separate model in Microsolt Excel provides transport efliciency through the oplical system and includes coating cfficiency, absorptance and scatter along with bulk ahsorption and scatter. Surface contamination can be added as shown in Figure 3 for relatively clean optical surfaces. When optical surfaces are found to be dirty, the individual optics can be measured and the corresponding reflection, absomption. and scattering losses can be added to compare whe measured transpont officiency so that the loss budget can he recomiled. The assumptions for mechanisms are

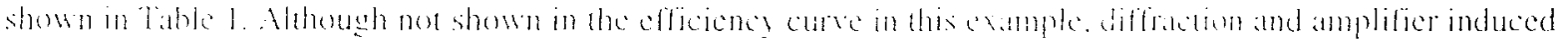

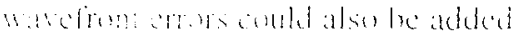


assumptions for mechanisms are shown in Table 1. Although not shown in the efficiency curve in this example, diffraction and amplifier induced wavefront errors could also be added.

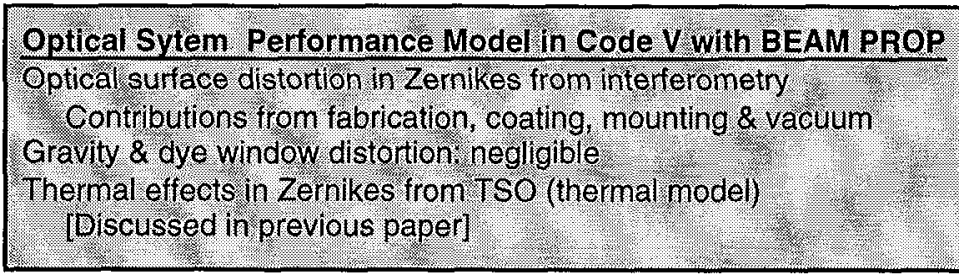

Optical Svstem Transport Efficiency Model
Buik material losses for transmissive optics
Scatter tor substrate surfaces
Coating erficiency.

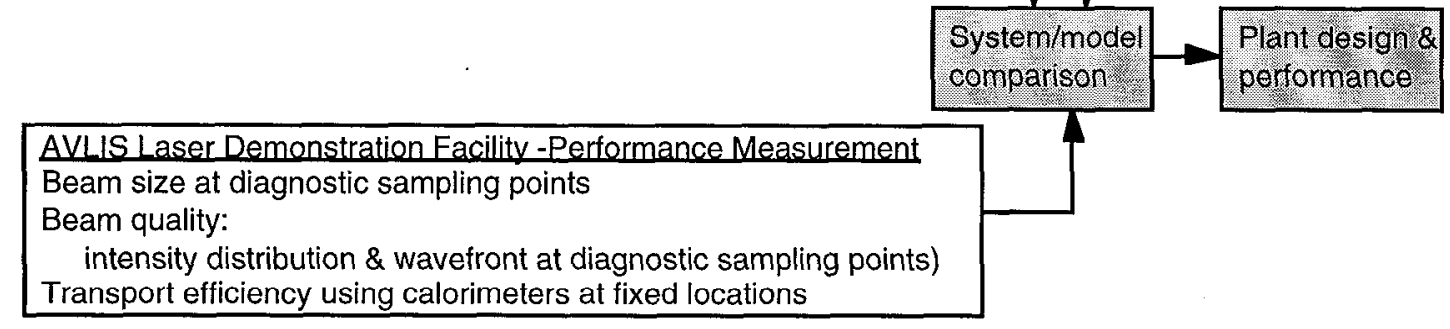

Fig. 2 Optical system performance model

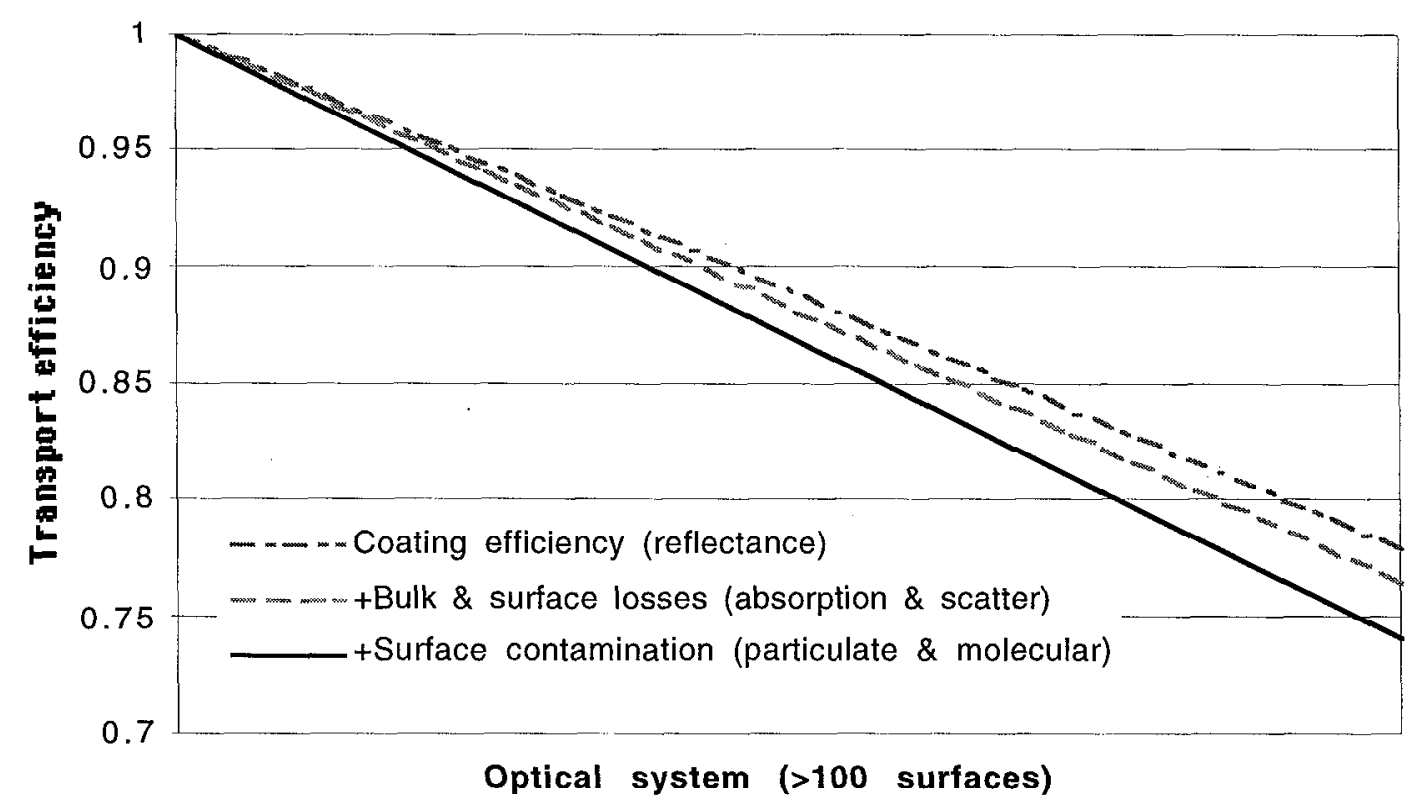

Fig. 3 Predicted optical system transport efficiency 
Table 1. Assumed losses for transport efficiency

\begin{tabular}{|lc|}
\hline Assumed optic losses \\
\\
\hline Mirror (HR) transmittance & $0.001-0.002$ \\
Antireflection reflectance & $0.002-0.003$ \\
HR / AR coating absorptance & 0.000010 \\
Control coating absorptance & 0.000050 \\
E-beam coating scatter & 0.000500 \\
IBS coating scatter & 0.000050 \\
Fused silica bulk abs. $(/ \mathrm{cm})$ & 0.000050 \\
Fused silica bulk scatter $(/ \mathrm{cm})$ & 0.000005 \\
\hline
\end{tabular}

\begin{tabular}{|c|c|}
\hline $\begin{array}{l}\text { Assumed losse } \\
\text { contamination }\end{array}$ & es for \\
\hline Reflection loss & 0.000100 \\
\hline Absorption loss & 0.000010 \\
\hline Scatter loss & 0.000100 \\
\hline
\end{tabular}

\begin{tabular}{|l|}
\hline Losses not included \\
\hline Diffraction \& clipping \\
Wavefront errors \\
Temperature effects \\
\hline
\end{tabular}

\section{Status of optical specifications \& manufacturing}

The specifications for high power laser optics are shown in Table 2. These specifications emphasize high efficiency and survivability in the high power laser environment and performance stability over the range of temperature and humidity. Bulk and coating absorptance is addressed. Coating induced wavefront distortion is also controlled. Process control for stress balance in coatings has proven illusive. E-beam coatings have been optimized for high efficiency and survivability with simultaneous high low absorptance. E-beam coatings require extensive spectral and interferometric testing in a controlled humidity environment. Ion beam sputtered (IBS) coatings are insensitive to humidity, can be stress balanced for most applications and have been demonstrated to meet the specifications for high-power applications. This simplifies testing and provides better stability in use.

Table 2

Parameters over (530-1000 nm)

Substrate: Fused silica:

- low absorption

- size:

- index variation:

- internal defects: inclusion class 1

Substrate: Zerodur / IJIE:

- low expansion

- size

Coated surface:

- angle of incidence range:

- roughness:

- visual defects by high intensity light:

-wavefront distortion @633 nm

- efficiency

- absorptance

- survivability

- stability:

Operating environment:

- temperature

- pressurc
Optical specifications

Specification

$\leq 5 \times 10^{-6} / \mathrm{cm}$

$25-178 \mathrm{~mm}$

$<10^{-6}$

$\leq 0.28 \mathrm{~mm}$ cross section

$\leq 50 \times 10^{-9} / \mathrm{K} @ 0-50^{\circ} \mathrm{C}$

$25-178 \mathrm{~mm}$ dia. \& $670 \mathrm{~mm}$ length

$0-60^{\circ}$

$<10 \AA$ RMS

$10 / 5$ (microscope aided)

$<0.05$ waves $\mathrm{p}-\mathrm{v}$

$>0.998 /$ surface

$<10^{-5}$ ( $\leq 5 \times 10^{-5}$ for beamsplitters)

$1-10 \mathrm{kw} / \mathrm{cm}^{2}$ (1-50 kw/ $\mathrm{cm}^{2}$ for ARs)

over time, power $\&$ environment

$0-50^{\circ} \mathrm{C}$

760 Torr (30 - 50\% RII) or $10^{-5}$ Torr 
Attention to detail during the manufacturing processes is very important. For several applications involving. rectangular shaped mirrors, it has been necessary to anneal the substrate material before and after both the fabrication and coating processes. Without the in-process annealing to remove residual stresses, it was not always possible to maintain the 0.05 wave $\mathrm{p}-\mathrm{v}$ reflected wavefront specifications.

Special test equipment has been needed in order to assist manufacturers in achieving the specifications or to verify that the specifications have been met. ${ }^{6}$ This includes laser reflectometers which provide sensitive measurements for measuring reflectance of high efficiency mirrors. Absorptance and survivability measurements can be made using systems based on the principle of photothermal deflection for absorptance and survivability. ${ }^{7}$ Total internal reflection microscopy (TIRM) is used to detect subsurface damage. ${ }^{8}$ Interferometry and spectral measurements are performed in special enclosures that provide vacuum or controlled temperature and humidity conditions.

Optical coating performance has been observed to degrade under the combination of high-average-power laser energy density at visible wavelengths and vacuum conditions. This phenomenon has been studied and found to be reversible if prevented from degrading too far. The effect can also be mitigated through variations in the environmental system. This interesting effect will be further discussed in a future report.

Two optical parameters were recently studied because of their potential impact on beam quality. These were bulk absorption of fused silica and the edge effects of optics outside the clear aperture that were observed to be both a source of component heating and damage. These effects are described below.

\section{Bulk absorption}

Fused silica was selected for all high-power transmissive applications. This was based on the combined effects of the change in dimension and index of refraction on changes in temperature and the bulk absorption induced temperature rise. The bulk absorption of the fused silica windows in the transport system has a significant impact on beam quality. There is currently no effort to monitor the bulk absorption of fused silica at visible wavelengths. Absorption in fused silica is too low to be observed by anything but the most sensitive test methods such as calorimetry. Two methods were proposed to monitor the bulk absorption. The first method monitors impurities in the material. Suppliers do not routinely monitor impurities due to the associated cost. The second was to measure the absorption directly through a photothermal deflection (PTD) technique. There are issues concerning sensitivity and calibration associated with both methods.

Glow Discharge Mass Spectrometry (GDMS) was used to measure impurities. The first step was comparison against NIST standards. Figure 4 shows GDMS measurements of a NIST standard that shows good correlation. Two NIST standards were tested with comparable results. 


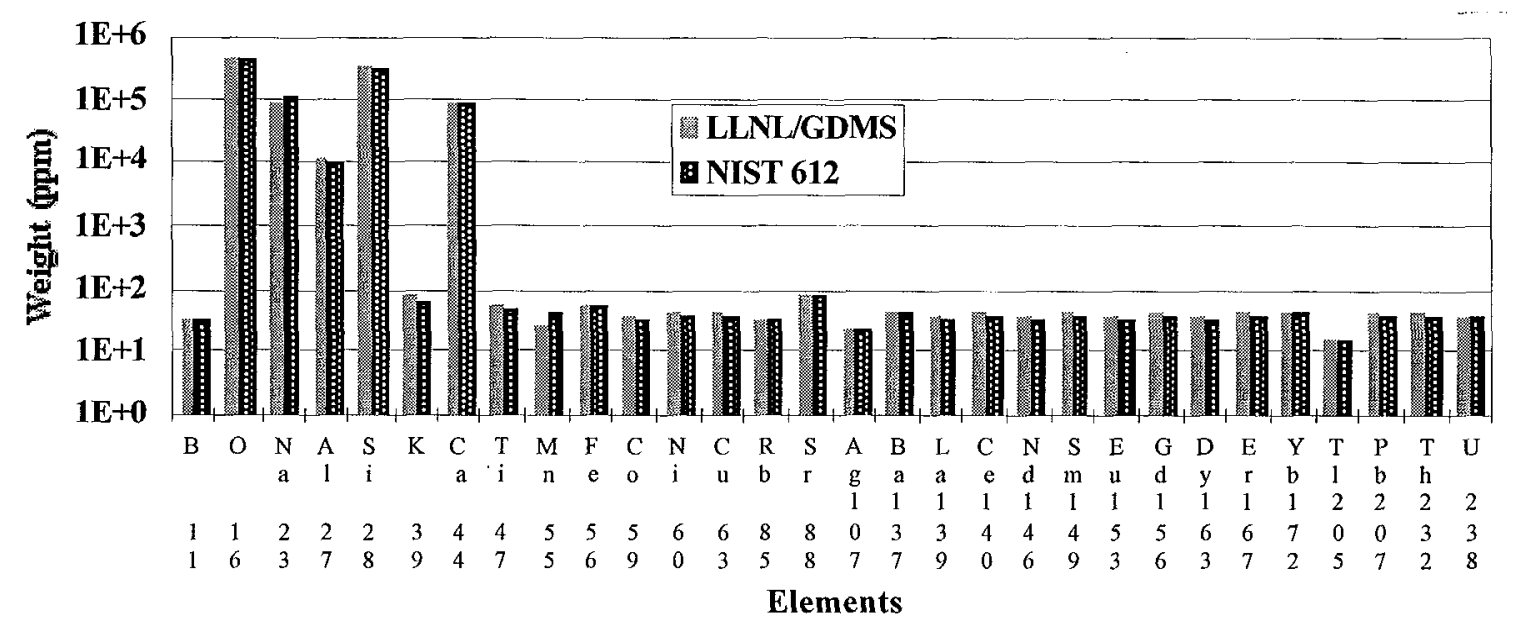

Fig. 4 Comparison of a NIST standard to GDMS measurement

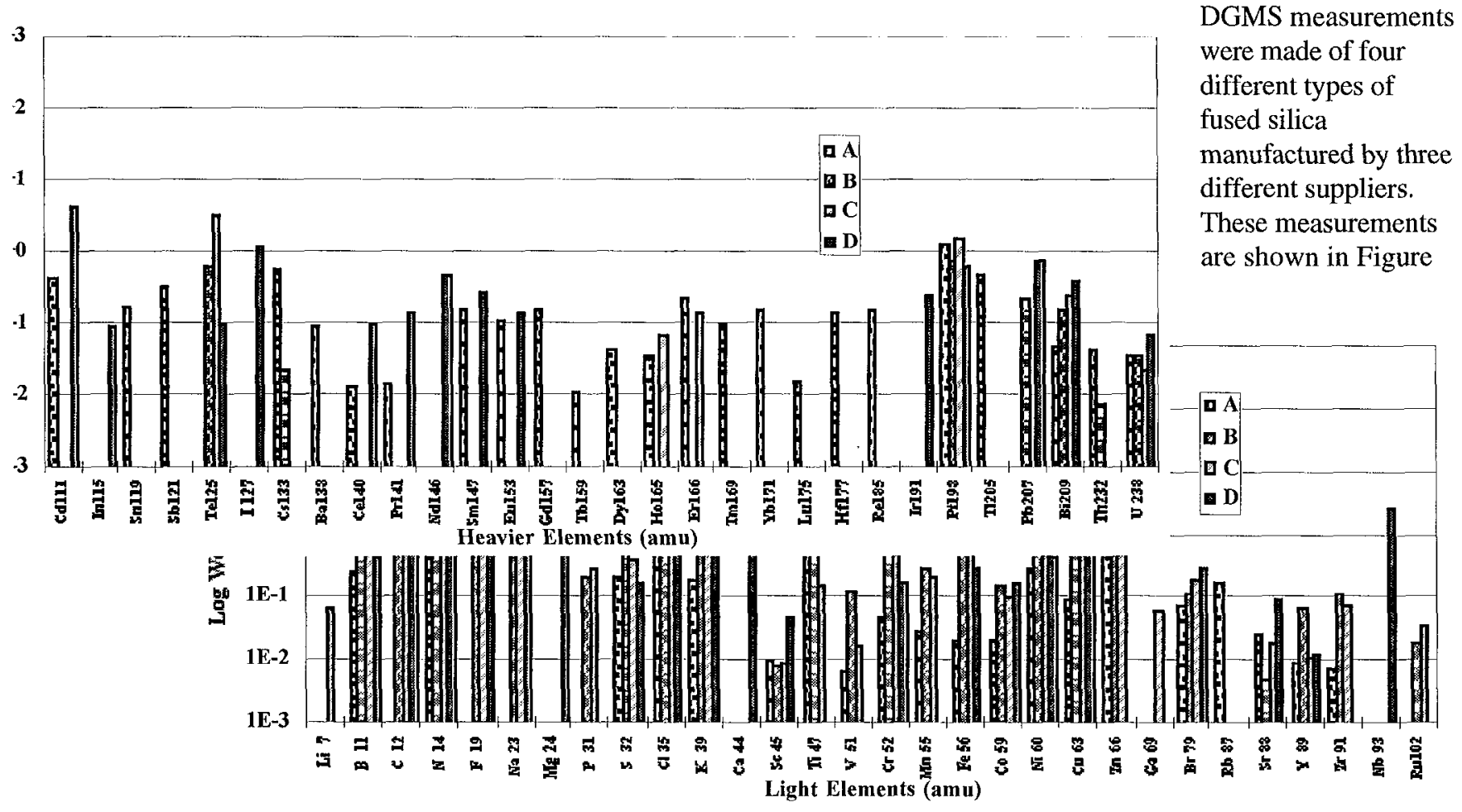

5. Significant differences can be observed between the different types of fused silica for some elements. The method has sufficient sensitivity to be a useful tool for evaluating the differences in impurities between individual boules of fused silica. To be useful in grading material for absorption, better understanding is needed that correlates the contributions to absorption from the various elements. This information can be provided by the PTD absorption measurements. Further effort is needed to complete this work. 
Fig. 5 Comparison of impurities in commercial fused silica

Edge effects of optics and coatings

For an optical system with long path lengths and over 100 surfaces, misaligned beams and light scattered and diffracted out of the main beam can fall on the edge of the coating, the uncoated substrate outside of the coating aperture, and on the edge bevel. These areas are not designed to handle laser energy. Absorption of the light can cause component heating and associated degradation of the beam quality. Component damage can also occur that in turn affects the system reliability. The temperature rise measured during tests of high power light on the areas outside of the coating aperture for a Zerodur mirror are shown in Figure 6 along with the comparison to the temperature rise of the coating. In the first case, the coating edge was produced by tooling in the coating run and leaves an uncoated rim around the optic. In the second case, the coating was deposited to the edge of the optic. This edge is relatively sharp and is referred to here as an "edge-break" without the typical bevel. This is done when high power light will fall near the edge of the optic. In both cases, the edge of the coating and edge of the optic experience much higher temperature than the coating when exposed to high power.

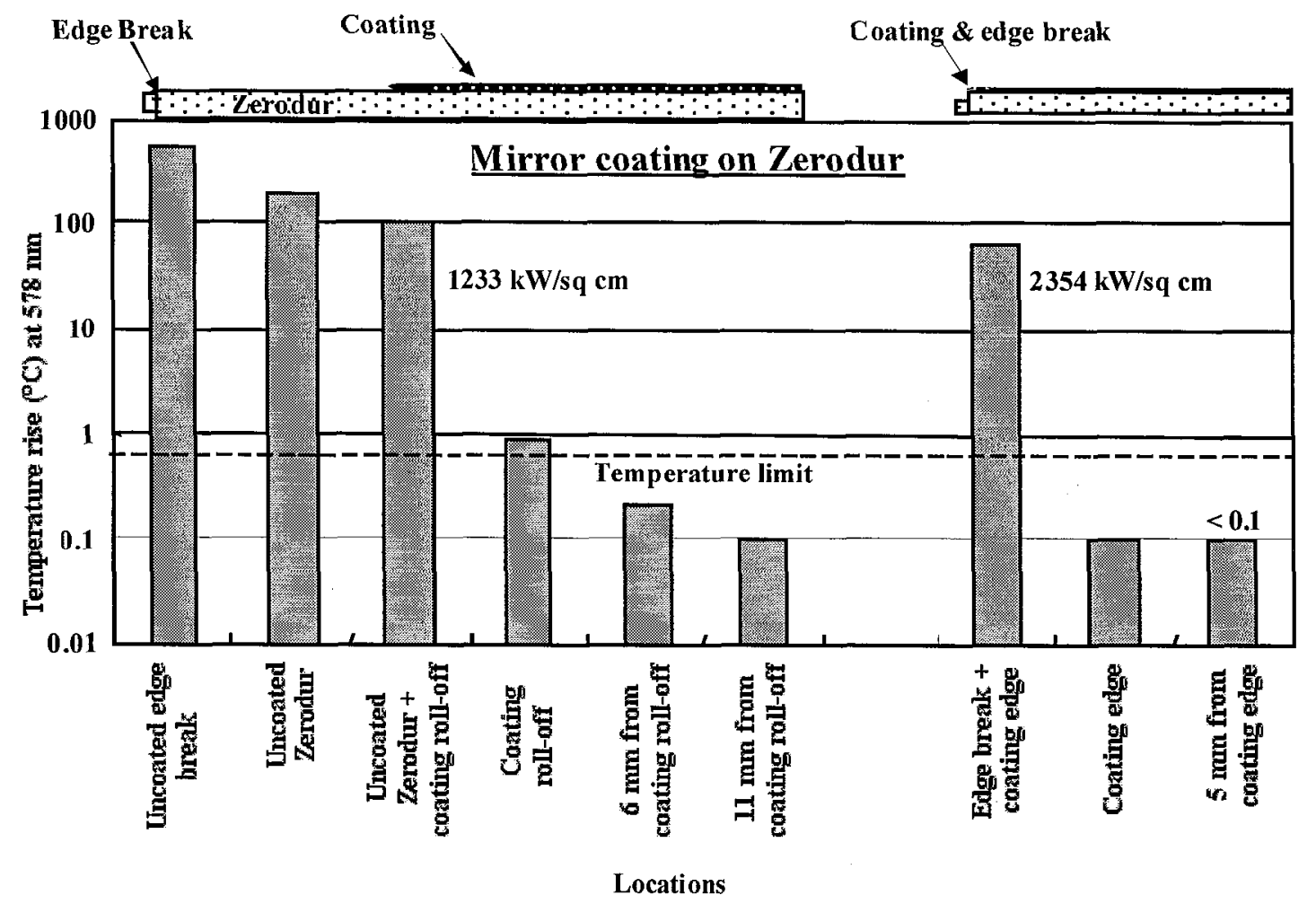

Fig. 6 Temperature rise of a mirror edge 
Tests were conducted to determine the ability of the coating edge, uncoated substrate, and edge bevel to survive under high-average-power light. Laser light at $578 \mathrm{~nm}$ was used to test a Zerodur mirror. The coating edge and bevel were only able to withstand about $10 \%$ of the power density that the coating could survive. Although direct high-power exposure of the edge of the optic was rare in the operating system due to good beam pointing and centering control, occasional excursions have occurred with resulting optic damage. These excursions also can fall on the adjacent mounts, which further contributes to optic heating and also typically

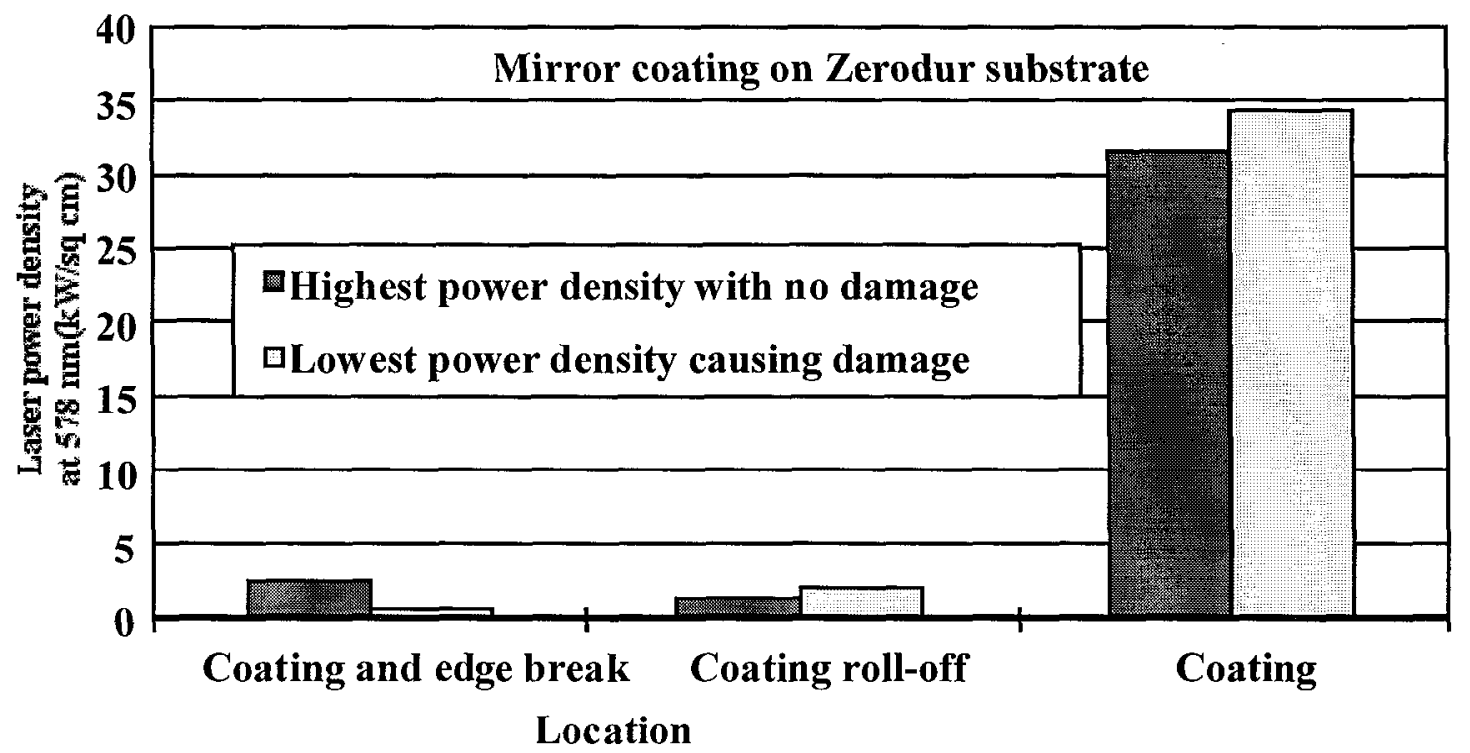

causes contamination of the optic surface. This precludes normal system operation even if the beam alignment is restored until the optic can be cleaned.

Fig. 7 Measured survivability and damage of a mirror edge

This is a detail of the optical design, which can be overlooked but can have a practical limitation on system performance. If it is not practical to make the optics larger in diameter, masks can be added to protect the optics from both direct exposure and scattered light. The masks will have to be water cooled if the beam excursion is more than an intermittent misalignment or if the scattered light energy is significant. Monitoring the temperature of the masks in key locations has proven to be a useful diagnostic tool for evaluating optical system performance.

\section{Summary}

A number of accomplishments have been demonstrated recently for AVLIS. This includes system performance using full-scale equipment although the planned scope of these tests has not been completed. Improvements in beam quality were achicved as a result of improvements in the adaptive optic systems and dye chain operation. Better tools for evaluating beam quality were deployed and better tools for modeling the optical system and vapor interactions werc developed. Optical component specifications were demonstrated to meet the basic requirements, although there were performance issues still being studied which implied further test requirements and possible specifications changes in the future. These are primarily in the area of bulk absorption and changes in coating performance over a range of power levels, environmental conditions, and time. The optical industry has demonstrated the ability to produce the high-performance optics required for high-average-power, visible lasers although specialized test equipment is needed to ensure process control and component performance. The AVLIS project is undergoing equipment shutdown and documentation pending possible future startup. 


\section{Acknowledgment and Auspices}

J. Michael Rodgers from Optical Research Associates and Tilman Stuhlinger from Ruda and Associates are acknowledged for their contribution to the end-to-model and diffraction modeling of optical subsystems. Linda Ault supported thermal analysis using TSO for the end-to-model. Bill Eickelberg provided the wavefront measurements on which error terms in the model were based. Tim Sarginson provided the measurements for the absorption and survivability of the optical edge effects. Joseph Menapace performed the GDMS testing.

This work was performed under the auspices of the U. S. Department of Energy by Lawrence Livermore National Laboratory under Contract W-7405-Eng-48.

\section{References}

1 J. Paisner, "Atomic Vapor Laser Isotope Separation" Applied Physics B 46, 253-260, Springer-Verlag.

2 K. Primdahl, R. Chow, J. Taylor, "Optical manufacturing requirements for an AVLIS plant" Proc. of SPIE on Optical Manufacturing and Testing II, Vol. 3134, San Diego, 1997.

3 J. Taylor, R. Chow, K. Primdahl, J. Willis, J. Wong, "Specification of optical components for a high average power laser environment" Proc. of SPIE on Optical Manufacturing and Testing II, Vol. 3134, San Diego, 1997

4 S. Cohen, R. E. English, C. Stolz, J. R. Taylor, "Thermal analysis of transmissive elements in high average power laser beam delivery systems", Proc. of SPIE, Vol. 1624, pp.411-422

5 R. Chow, L. Ault, J. Taylor, D. Jedlovec, "Thermally-induced distortion of an high average power laser system by an optical transport system" Proc. of SPIE on Optical Manufacturing and Testing III, Vol. 3782, Denver, 1999.

6 R. Chow, J. Taylor, K. Primdahl, "Testing of optical components to assure performance in a high average power environment" Proc. of SPIE on Optical Manufacturing and Testing II, Vol. 3134, San Diego, 1997

7 R. Chow, J. R. Taylor, Z. L. Wu, Yue Han, T. Yang, "Absorptance measurements of transmissive optical components by the surface thermal lensing technique" Proc. Of SPIE on Optical Materials for High Power Lasers, Vol. 3244-35, Boulder, 1997

8 Z. M. Liao, S. J. Cohen, J. R. Taylor, "Total internal reflection microscopy (TIRM) as a nondestructive subsurface damage assessment tool" Proc. Of SPIE on Optical Materials for High Power Lasers, Vol. 2428-40, Boulder, 1994 